\title{
Perfluorocyclohexenyl Aryl Ether Polymers via Polycondensation of Decafluorocyclohexene with Bisphenols
}

\author{
Babloo Sharma, ${ }^{1 *}$ Sarah C. Hill, ${ }^{2 *}$ Shawna M. Liff, ${ }^{3}$ William T. Pennington, ${ }^{2}$ \\ Dennis W. Smith Jr. ${ }^{1}$ \\ ${ }^{1}$ Department of Chemistry and The Alan G. MacDiarmid NanoTech Institute, The University of Texas at Dallas, \\ Richardson, Texas 75080 \\ ${ }^{2}$ Department of Chemistry, Clemson University, Clemson, South Carolina 29630 \\ ${ }^{3}$ Intel Corporation, Chandler, Arizona 85226 \\ Correspondence to: D. W. Smith Jr. (E-mail: dwsmith@utdallas.edu)
}

Received 23 August 2013; accepted 18 October 2013; published online 26 November 2013

DOI: 10.1002/pola.26995

ABSTRACT: A novel class of semifluorinated perfluorocyclohexenyl (PFCH) aryl ether homo/copolymers was successfully synthesized with high yield through the step-growth polymerization of commercially available bisphenols and decafluorocyclohexene in the presence of a triethylamine base. The synthesized polymers exhibit variable thermal properties depending on the functional spacer group (R). PFCH aryl ether copolymers with random and alternating architectures were also prepared from versatile bis-perfluorocyclohexenyl aryl ether monomers. The $\mathrm{PFCH}$ polymers show high thermal stabilities with a $5 \%$ decomposition temperature ranging from 359 to $444{ }^{\circ} \mathrm{C}$ in air and nitrogen atmosphere. These semifluorinated $\mathrm{PFCH}$ aromatic ether polymers contain intact enchained $\mathrm{PFCH}$ olefin moieties, making further reactions such as crosslinking and application specific functionalization possible. (c) 2013 Wiley Periodicals, Inc. J. Polym. Sci., Part A: Polym. Chem. 2014, 52, 232-238

KEYWORDS: addition-elimination reaction; fluoropolymers; polycondensation; polyethers; step-growth polymerization
INTRODUCTION Fluoropolymers exhibit high thermal stability, chemical inertness, low surface energy, unique surface properties, low refractive index (RI), low dielectric constant, and low optical loss at telecom wavelength. ${ }^{1-5}$ Fluorinated materials with low transmission loss over telecommunication wavelength, low RI, low moisture absorption, and high thermal stability are excellent candidates for optical and photonic applications, such as matrices for electro-optic (EO) applications or nonlinear optics applications. ${ }^{5-8}$ Typically, replacing $\mathrm{C}-\mathrm{H}$ bonds with $\mathrm{C}-\mathrm{F}$ bonds will result in extremely low absorption in the wavelength range of interest. Additional stability can be achieved via further crosslinking, which improves thermal properties and solvent resistance. ${ }^{9,10}$ Therefore, innovative ways are continually being explored to incorporate fluorine in polymeric architectures, with a desired crosslinkable site. Synthetic crosslinkable fluoropolymers are highly sought for a variety of applications, ranging from gas separation membranes, PEM membranes, EO and microelectronics, as well as lithography applications.

Perfluorocyclobutyl (PFCB) aryl ether polymers and fluorinated arylene vinylene ether (FAVE) polymers, both polyfluoropolyethers (PFPEs), derived from aromatic trifluorovinyl ether (TFVE) monomers, have been extensively explored as waveguides, hole transport materials and passive host materials for next generation optical applications (Scheme 1). . $^{5,11-13}$ However, cumbersome multistep synthesis of TFVE monomers presents a time and energy-consuming hurdle. ${ }^{14}$ Therefore, new semifluorinated aromatic polymers that are time and cost efficient are highly desirable.

Decafluorocyclohexene (DFCH), along with octafluorocyclopentene (OFCP), and hexafluorocyclobutene (HFCB) are readily available perfluorocycloalkenes (PFCAs) that exhibit unique chemistry. Unlike OFCP and HFCB, DFCH is relatively easier to handle because of its high boiling point and comparatively low toxicity. ${ }^{15}$ As the literature suggests, pefluorocycloalkenes are averse to homopolymerization via free radical reactions, with few exceptions, such as Teflon® ${ }^{\circledR} F^{2,16}$ However, PFCAs form copolymers via a free radical mechanism with electron rich olefinic monomers with low mole \% of fluorinated monomer. ${ }^{16}$ Also, similarly to other PFCAs, DFCH has shown reactivity with various nucleophiles including enolates, ${ }^{17}$ azoles, ${ }^{18}$ phenol, ${ }^{19}$ alkoxides, ${ }^{20}$ amines, ${ }^{21}$ and arenethiolates. $^{22}$ DFCH derivatives have been used as

*Babloo Sharma and Sarah C. Hill have contributed equally to this work

Additional Supporting Information may be found in the online version of this article.

(C) 2013 Wiley Periodicals, Inc. 
(a)<smiles>FC(F)=C(F)Oc1cc[X](-c2ccc(OC(F)=C(F)F)cc2)cc1</smiles>

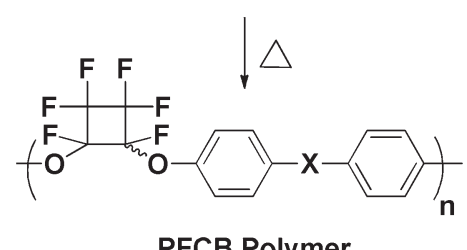

(b)

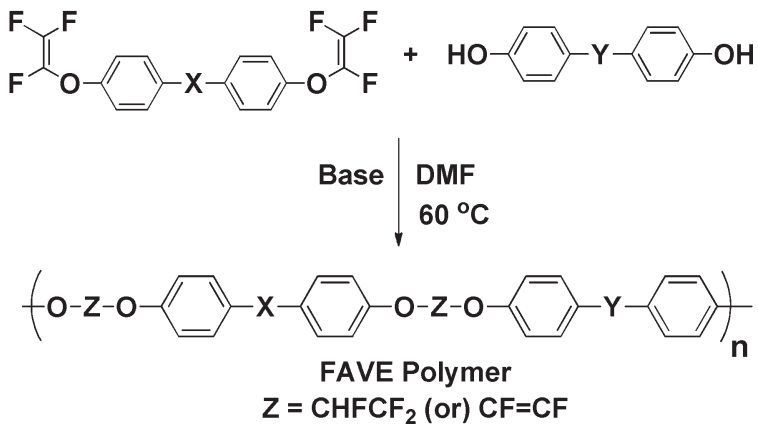

SCHEME 1 Synthesis of (a) PFCB polymers and (b) FAVE polymers from TFVE monomers.

lubricants, ${ }^{23}$ foam blowing agents and fire extinguishers, ${ }^{24-26}$ refrigerants or heat transfer agents, ${ }^{24,27}$ chromophores, ${ }^{22}$ and organic light emitting devices. ${ }^{28}$ Apparently, several small molecular derivatives have been synthesized from $\mathrm{DFCH}$, but to our knowledge, there is a dearth of polymers derived from this fluorine-enriched molecule. However, the step-growth polymerization of decafluorocycloalkene with bis-nucleophiles has not been reported.

In this manuscript, we extend our recently published work on perfluorocyclopentenyl (PFCP) aryl ether polymers and perfuorocycloalkenyl (PFCA) aryl ether monomers, ${ }^{19,29}$ and report the synthesis of a new class of fluoropolymers, namely, perfluorocyclohexenyl (PFCH) aryl ether polymers, via step-growth polycondensation. This reaction represents an addition-elimination reaction of bisphenols with DFCH in the presence of a base, triethylamine (Scheme 2). These polymers were obtained in good yields and show variable thermal properties, depending on the functional spacer group, R (Table 1). This new class of semifluorinated PFCH aromatic ether polymers (Scheme 2) retains enchained olefin functionality for branching and postreactivity such as crosslinking and application-specific functionalization. The observed PDI of more than 2.0 indicates branching, as expected. Initial studies have shown gel formation upon reaction of these PFCH aryl ether polymers with dinucleophiles, and will be part of a future manuscript.

This initial observation was confirmed via experimental results, as the polymerization reaction leads to gel formation after a particular reaction time. Therefore, the reaction time is crucial for obtaining a processable thermoplastic $\mathrm{PFCH}$ aryl ether polymer.

\section{EXPERIMENTAL}

\section{Chemical Reagents}

DFCH (97\%) was purchased from Synquest Laboratories and used as received. Bisphenols, triethylamine, dimethylformamide (DMF), tetrahydrofuran (THF), deuterated solvents, and all other chemicals were purchased from Alfa Aesar Company and used as received, unless otherwise stated.

\section{Instrumentation}

All PFCH aryl ether polymers were fully characterized via ${ }^{1} \mathrm{H}$ and ${ }^{19} \mathrm{~F}$ NMR spectroscopy, attenuated total reflectance- fourier transform infrared (ATR-FTIR) spectroscopy, wide-angle X-ray diffraction (WAXRD), size exclusion chromatography (SEC), differential scanning calorimetric (DSC), and thermal gravimetric analysis (TGA) analyses. NMR spectroscopy was performed on Bruker ADVANCED IIITM $500 \mathrm{MHz}$ spectrometer. Chemical shifts were measured in ppm $(\delta)$ with reference to deuterated acetone (2.09 $\mathrm{ppm}) /$ deuterated THF (1.85 ppm) and trichlorofluoromethane $(0 \mathrm{ppm})$ for ${ }^{1} \mathrm{H}$ and ${ }^{19} \mathrm{~F}$ NMR, respectively. Attenuated total reflectance Fourier transform infrared (ATR-FTIR) spectroscopy was performed on a Thermo-Nicolet Magna 550 FIR spectrophotometer with a high endurance diamond ATR attachment. Molecular weights were obtained via size exclusion chromatography analysis performed on a Viscotek VE 3580 system equipped with a VisoGEL column (GMHHR-M), connected to a RI detector, calibrated with polystyrene as standard. DSC analysis was done on a Mettler Toledo DSC 1 system in nitrogen atmosphere with heating and cooling rate of $10{ }^{\circ} \mathrm{C} / \mathrm{min}$. The $T_{\mathrm{g}}$ and $T_{\mathrm{m}}$ of polymers were measured from the third heating cycle using Star E version 10.0 software suite. The thermal stability of PFCH polymers were measured in air and nitrogen atmospheres. For $\mathrm{N}_{2}$ atmosphere, TGA was performed on a Mettler Toledo TGA/DSC 1 LF instrument with a heating rate of $10{ }^{\circ} \mathrm{C} / \mathrm{min}$. For air atmosphere, TGA was

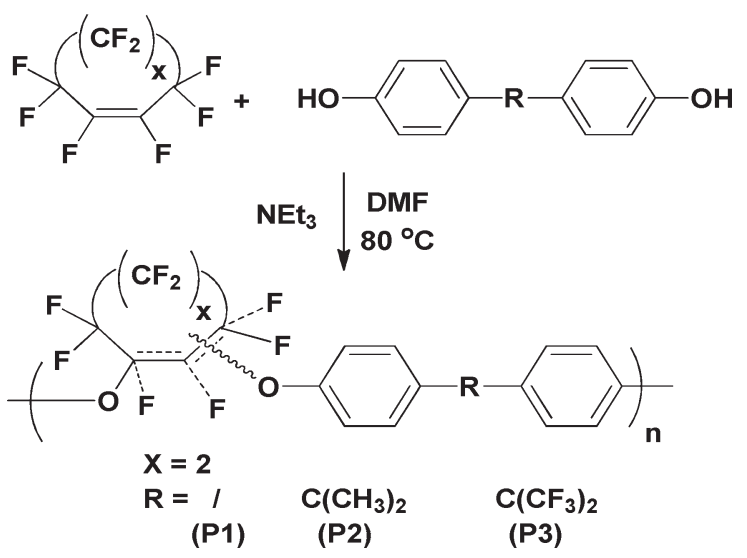

SCHEME 2 General chemical representation for perfluorocycloalkenyl (PFCA) aryl ether polymer synthesis. 
TABLE 1 Reaction of Bisphenols with DFCH

\begin{tabular}{|c|c|c|c|c|c|c|c|c|}
\hline $\mathrm{PFCH}$ & $\begin{array}{l}\text { Reaction } \\
\text { Time (h) }\end{array}$ & $M_{\mathrm{n}}$ & $M_{\mathrm{w}}$ & $\mathrm{PDI}^{\mathrm{a}}$ & $T_{\mathrm{g}}\left({ }^{\circ} \mathrm{C}\right)^{\mathrm{b}}$ & $\begin{array}{l}T_{\text {d } 5 \%} \\
\left(\text { in } \mathrm{N}_{2}\right)\left({ }^{\circ} \mathrm{C}\right)\end{array}$ & $\begin{array}{l}T_{\text {d } 5 \%} \\
\text { (in Air) }\left({ }^{\circ} \mathrm{C}\right)\end{array}$ & Yield $(\%)^{c}$ \\
\hline Homopolymer P1 & 9 & 15,600 & 35,600 & 3.3 & 132 & 388 & 383 & 88 \\
\hline Homopolymer P2 & 24 & 13,700 & 29,900 & 2.1 & 90 & 383 & 359 & 67 \\
\hline Homopolymer P3 & 5 & 9,400 & 24,000 & 2.5 & 132 & 406 & 392 & 77 \\
\hline Copolymer P1-co-P3 & 18 & 13,600 & 54,800 & 4.0 & 131 & 409 & 381 & 77 \\
\hline Copolymer (M3-alt-BP) & 24 & 15,000 & 47,000 & 3.1 & 108 & 394 & 392 & 75 \\
\hline Copolymer (M2-alt-BP) & 24 & 19,900 & 44,000 & 2.2 & 128 & 444 & 378 & 92 \\
\hline
\end{tabular}

performed on a TA Instrument - Q600 SDT Simultaneous DSC-TGA instrument with heating rate of $10{ }^{\circ} \mathrm{C} / \mathrm{min}$. WAXRD analysis were performed on a Rigaku Ultima IV X-ray diffractometer with $\mathrm{Cu} \mathrm{K} \alpha 1$ radiation $(\lambda=1.54060 \AA)$, using a $2 \theta$ scan range of $5-35^{\circ}$.

\section{Synthesis of Homopolymer P1}

In a $100-\mathrm{mL}$ single-necked round bottom flask equipped with magnetic stirrer, weighed $0.700 \mathrm{~g}$ (3.76 mmol) of 4,4'biphenol, $1.712 \mathrm{~g}$ (16.92 mmol) of triethylamine, and $1.0 \mathrm{~mL}$ of anhydrous DMF was added. Flask was closed with rubber septum. The solution was stirred and purged with nitrogen for $10 \mathrm{~min}$, followed by addition of $0.985 \mathrm{~g}$ (3.76 $\mathrm{mmol})$ of DFCH. The solution was heated for $9 \mathrm{~h}$ at $80{ }^{\circ} \mathrm{C}$, then the reaction mixture was cooled to room temperature, and the polymer was precipitated in $\mathrm{CH}_{3} \mathrm{OH}$. The polymer was dissolved in THF and reprecipitated in $\mathrm{CH}_{3} \mathrm{OH}$ to give $1.35 \mathrm{~g}$ of white-colored polymer (yield $=88 \%$ ).

${ }^{1} \mathrm{H}$ NMR (500 MHz, acetone- $\left.d_{6}, \delta\right): 6.93(\mathrm{~m}), 7.54(\mathrm{~m}) \cdot{ }^{19} \mathrm{~F}$ NMR (470 MHz, acetone- $\left.d_{6}, \delta\right)$ : -114.87 (brs), -133.19 (brs). FTIR ( $v, / c m): ~ 821,970,997,1163,1193,1273,1492$, 1602, 1668, 1708.

\section{Synthesis of Homopolymer P2}

Homopolymer P2 was synthesized from bisphenol A by following the same method as $\mathbf{P 1}$, except the reaction time was prolonged to $24 \mathrm{~h}$, giving a white polymer after drying (yield $=67 \%$ ).

${ }^{1} \mathrm{H}$ NMR (500 MHz, acetone- $d_{6}, \delta$ ): 1.66 (brs, 6H), 6.73 (brs), 6.85 (brs), 7.11 (brs), 7.29 (m). ${ }^{19} \mathrm{~F}$ NMR (470 MHz, acetone$d_{6}, \delta$ ): -114.85 (brs), -133.34 (brs). FTIR $(v, / \mathrm{cm}): 829$, 970, 999, 1166, 1274, 1504, 1602, 1666, 1738.

\section{Synthesis of Homopolymer P3}

Homopolymer P3 was synthesized from bisphenol 6F by following the same method as $\mathbf{P 1}$, except the reaction time was reduced to $5 \mathrm{~h}$, giving a white polymer after drying (yield $=77 \%$ ).

${ }^{1} \mathrm{H}$ NMR (500 MHz, acetone- $d_{6}, \delta$ ): $6.79(\mathrm{~m}), 7.43(\mathrm{~m}) .{ }^{19} \mathrm{~F}$ NMR (470 MHz, acetone- $d_{6}, \delta$ ): $-63.82(\mathrm{~s}),-115.36$ (brs), -133.44 (brs). FTIR $(v, / \mathrm{cm}): 827,970,1001,1172,1510$, 1608, 1668, 1732.

\section{Synthesis of Copolymer (P1-co-P3)}

In a 100-mL single-necked round bottom flask equipped with magnetic stirrer, weighed $1.026 \mathrm{~g}(3.05 \mathrm{mmol})$ of bisphenol 6F, $0.568 \mathrm{~g}$ (3.05 mmol) of 4,4'-biphenol, $2.471 \mathrm{~g}$ (24.42 mmol) of triethylamine, and $1.5 \mathrm{~mL}$ of anhydrous DMF was added. The solution was stirred and purged with nitrogen for $10 \mathrm{~min}$, followed by addition of $1.60 \mathrm{~g}$ (6.11 mmol) of DFCH. The solution was heated at $80{ }^{\circ} \mathrm{C}$ for $18 \mathrm{~h}$, then the reaction mixture was cooled to room temperature, and the polymer was precipitated in $\mathrm{CH}_{3} \mathrm{OH}$. The polymer was dissolved in THF and reprecipitated in $\mathrm{CH}_{3} \mathrm{OH}$ to give $2.27 \mathrm{~g}$ of white colored polymer (yield $=77 \%$ ).

${ }^{1} \mathrm{H}$ NMR (500 MHz, acetone- $d_{6}, \delta$ ): $6.92(\mathrm{~m}), 7.46(\mathrm{~m}) .{ }^{19} \mathrm{~F}$ NMR (470 MHz, acetone- $d_{6}, \delta$ ): -63.58 (brs), -114.81 (brs), -133.16 (brs). FTIR ( $v, / \mathrm{cm}): 825,970,999,1172,1492$, 1606, 1668, 1737.

\section{Synthesis of Copolymer (M2-alt-BP)}

In a $100-\mathrm{mL}$ single-necked round bottom flask equipped with magnetic stirrer, weighed $0.637 \mathrm{~g}(0.90 \mathrm{mmol})$ of M2, $0.166 \mathrm{~g}(0.90 \mathrm{mmol})$ of 4,4'-biphenol, $0.407 \mathrm{~g}$ (4.03 $\mathrm{mmol})$ of triethylamine, and $1.0 \mathrm{~mL}$ of anhydrous DMF was added. The solution was stirred and purged with nitrogen for 10 min, then the solution was heated at $80{ }^{\circ} \mathrm{C}$ for $24 \mathrm{~h}$. The solution was cooled to room temperature, and the polymer was precipitated in $\mathrm{CH}_{3} \mathrm{OH}$. The polymer was dissolved in THF and reprecipitated in $\mathrm{CH}_{3} \mathrm{OH}$ to give $0.546 \mathrm{~g}$ of white colored polymer (yield $=92 \%$ ).

${ }^{1} \mathrm{H}$ NMR (500 MHz, acetone- $d_{6}, \delta$ ): 1.63 (brs, 6H), $6.79(\mathrm{~m})$ ), $7.38(\mathrm{~m}) .{ }^{19} \mathrm{~F}$ NMR $\left(470 \mathrm{MHz}\right.$, acetone- $\left.d_{6}, \delta\right):-114.56$ (brs), -114.95 (brs), -133.21 (brs). FTIR ( $v, / \mathrm{cm}):$ 823, 970, 997, 1166, 1274, 1492, 1602, 1666, 1707.

\section{Synthesis of Copolymer (M3-alt-BP)}

Copolymer (M3-alt-BP) was synthesized from M3 using the same method and reaction conditions as copolymer (M2-altBP), giving a white polymer after drying (yield $=75 \%$ ).

${ }^{1} \mathrm{H}$ NMR (500 MHz, acetone- $d_{6}, \delta$ ): $6.88(\mathrm{~m}), 7.43(\mathrm{~m}) .{ }^{19} \mathrm{~F}$ NMR (470 MHz, acetone- $d_{6}, \delta$ ): -63.61 (brs), -114.83 (brs), -133.32 (brs). FTIR ( $v, / \mathrm{cm}): 823,974,999,1170,1492$, 1606, 1666, 1737. 


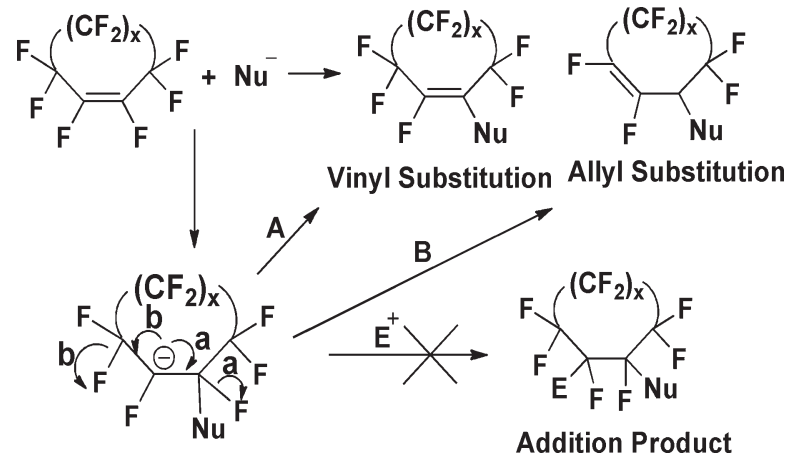

SCHEME 3 General reaction representation for addition-elimination reactions on perfluorocycloalkenes.

\section{RESULTS AND DISCUSSION}

Table 1 presents the yields, molecular weights, and thermal properties ( $T_{\mathrm{g}}$ and $\left.T_{\mathrm{d}}{ }_{5 \%}\right)$ of $\mathrm{PFCH}$ homopolymers and copolymers. These polymers were synthesized via the same methodology but with different reaction times. The heating time for each reaction was assigned to avoid gel formation due to the different reactivities of the starting materials toward polycondensation.

During step-growth polymerization, the nucleophile attacks the fluorinated olefin, resulting in the carbanion, which can eliminate fluoride via route $\mathrm{A}$, resulting in vinyl substitution, or via route $B$, resulting in allyl substitution (Scheme 3). ${ }^{19,20,30}$ As shown in our recent work with $\mathrm{DFCH},{ }^{18}$ both products are observed with the vinyl substituted product as the major product (supported by NMR data). Thus, the general representation of $\mathrm{PFCH}$ aryl ether polymers can be shown as Figure 1, where $p>q+r$, as evident from NMR spectra. Also, these PFCH aryl ether polymers do not yield any addition product, unlike what is observed for FAVE polymers. ${ }^{12,31,32}$

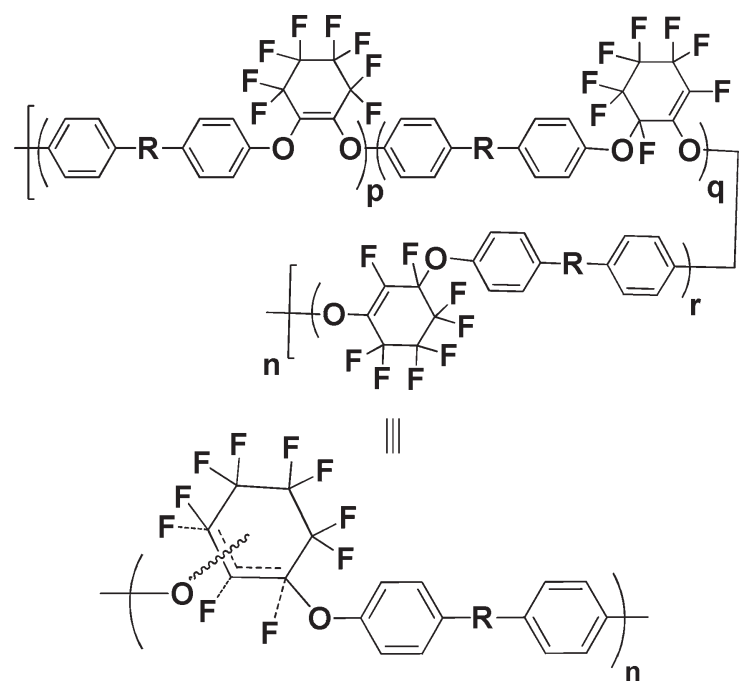

FIGURE 1 General representation of PFCH aryl ether polymers.
A series of copolymers were synthesized via direct polymerization reaction from the commercially available feedstocks bisphenols and DFCH, and also from the recently published bis(PFCH) aryl ether monomers, to yield polymers with random and/or alternating architecture (Scheme 4, Table 1). Bis(PFCH) aryl ether monomers (M2 and M3) were synthesized from commercially available feedstocks in good yield and characterized as reported elsewhere. ${ }^{19}$ Further, the stepgrowth polycondensation reaction of these monomers with other bisphenols in stochiometric ratio (1:1) led to copolymers with alternating arylene ether architectures (Scheme 4). As Table 1 shows, these copolymers also yield high thermal stability and variable $T_{\mathrm{g}}$, similar to their homopolymer counterparts.

All homo/copolymers were characterized via ${ }^{1} \mathrm{H}$ NMR and ${ }^{19} \mathrm{~F}$ NMR. As aforementioned, these polymers have vinyl and allyl substitution on the PFCH ring, resulting in asymmetry in the polymer unit. This accounts for asymmetry in the polymer chain and the absence of a doublet of doublet (dd) pattern in ${ }^{1} \mathrm{H}$ NMR, as was expected for a polymer with only vinyl substitution. For example, homopolmer P1 shows multiplets over the range 6.6-7.2 and 7.2-7.9 ppm (Supporting Information Fig. S1). The allyl substitution also yielded small, uncounted peaks in ${ }^{19} \mathrm{~F}$ NMR, as seen in Figure 2, with the ${ }^{19} \mathrm{~F}$ spectra clearly showing the dominance of vinyl substitution. The high-intensity peaks show the vinyl substitution, whereas the small peaks from -115 to -160 exhibit the allyl substitution. Homopolymer P1 [Fig. 2(a)] shows two major resonance peaks corresponding to four side and four apex fluorines at -115 and -129 ppm, respectively. NMR spectra for other homopolymers and copolymers show the similar trend as homopolymer P1 (Fig. 2 and Supporting Information).
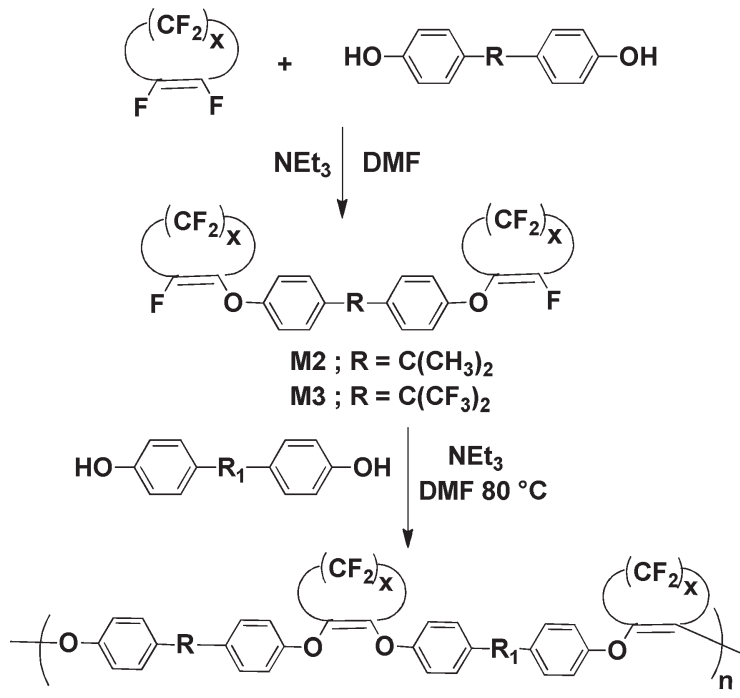

$$
\begin{gathered}
\text { Copolymer (M2-alt-BP); } \mathrm{R}=\mathrm{C}\left(\mathrm{CH}_{3}\right)_{2}, \mathrm{R}_{1}=I \\
\text { Copolymer (M3-alt-BP) } ; \mathrm{R}=\mathrm{C}\left(\mathrm{CF}_{3}\right)_{2}, \mathrm{R}_{1}=I \\
\mathrm{X}=\mathbf{4}
\end{gathered}
$$

SCHEME 4 Synthesis of perfluorocycloalkenyl (PFCA) aryl ether monomers and copolymers therefrom. 
(a)

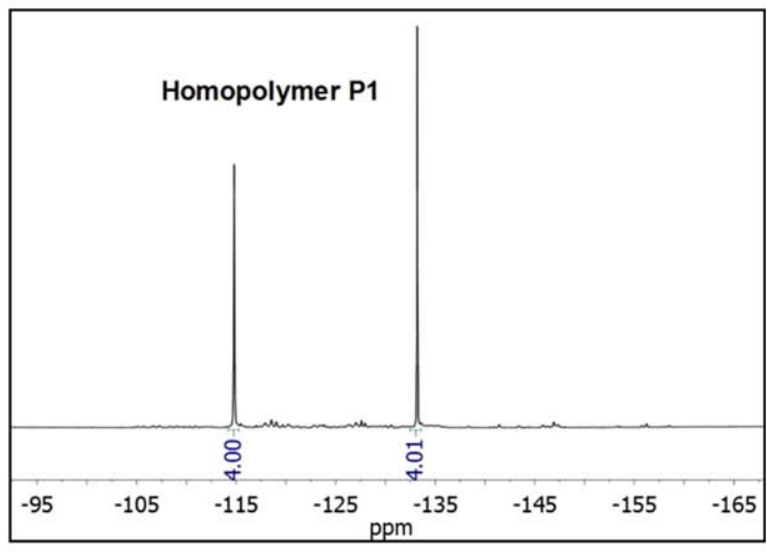

(b)

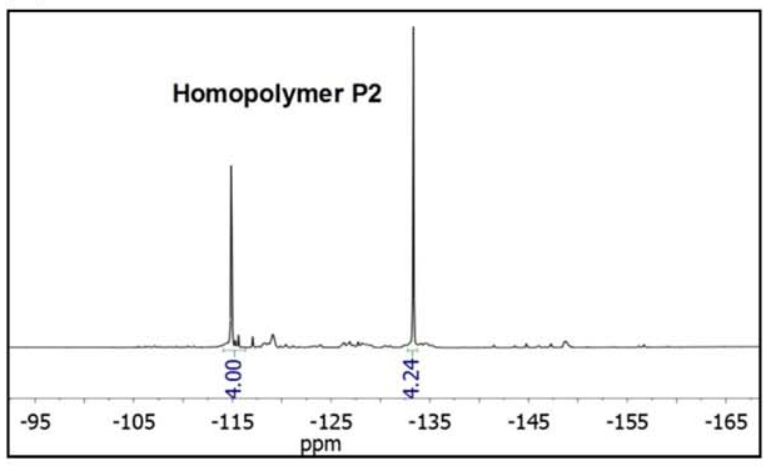

(c)

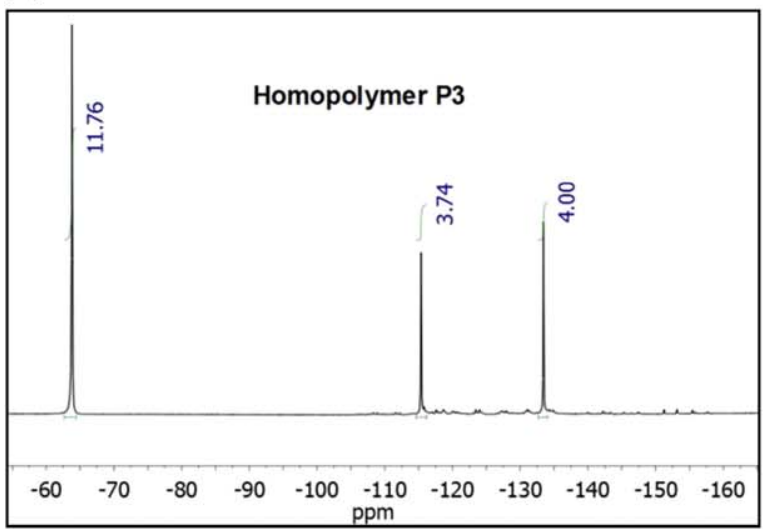

FIGURE $2{ }^{19} \mathrm{~F}$ NMR spectra $\left(470 \mathrm{MHz}\right.$, acetone- $d_{6}$, $\delta$; at room temperature) for homopolymers (a) P1, (b) P2, and (c) P3. [Color figure can be viewed in the online issue, which is available at wileyonlinelibrary.com.]

The thermal stability for these PFCH aryl ether polymers were measured via TGA analysis in nitrogen and air atmosphere. PFCH aryl ether polymers exhibit high thermal stabilities and a one-step degradation pattern in air as well as in nitrogen atmosphere. In $\mathrm{N}_{2}$ atmosphere, decomposition temperature $\left(T_{\mathrm{d}}\right)$ at $5 \%$ weight loss ranges from 380 to $440{ }^{\circ} \mathrm{C}$ [Fig. 3(a)], whereas it ranges from 359 to $392{ }^{\circ} \mathrm{C}$ in air atmosphere [Fig. 3(b)]. DSC thermogram for PFCH aryl ether polymers show variable glass transition temperatures $\left(T_{\mathrm{g}}\right)$ ranging from 90 to $132{ }^{\circ} \mathrm{C}$, depending on the spacer group, R. (Fig. 4). Bisphenol A disrupts the packing ability of polymer chains which decreases the $T_{\mathrm{g}}$ of the system in comparison to $\mathrm{PFCH}$ polymer derived from 4,4'-biphenol. The $6 \mathrm{~F}$ $\left(\mathrm{CF}_{3}\right)_{2}$ group imparts anomalous crystallinity to the system, thus synthesized homopolymer P3 displays a high $T_{\mathrm{g}}$, and higher relative crystallinity with a melting peak at $201{ }^{\circ} \mathrm{C}$ in its DSC thermogram [Fig. 4(b)]. This melting peak appears more predominant when the cooling process is very slow because it gives enough time to grow a larger crystal domain. The observed higher relative crystallinity was attributed to high fluorine content, as analogously observed for 6F-PFCP and 6F-PFCB aryl ether polymers. ${ }^{29,33}$

The semicrystalline nature of PFCH polymers was studied further via wide-angle X-ray diffraction (WAXRD), as shown in Figure 5. Homopolymer P1 exhibits a characteristic

(a)

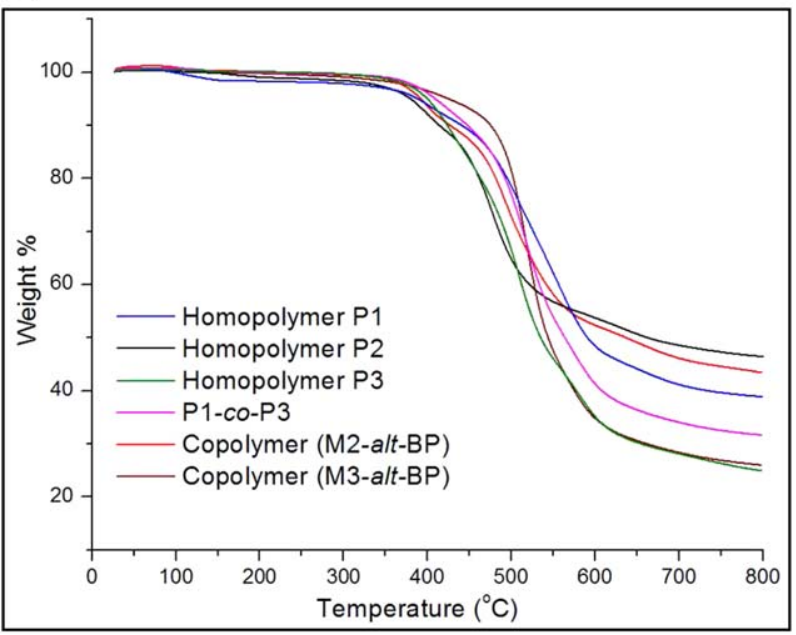

(b)

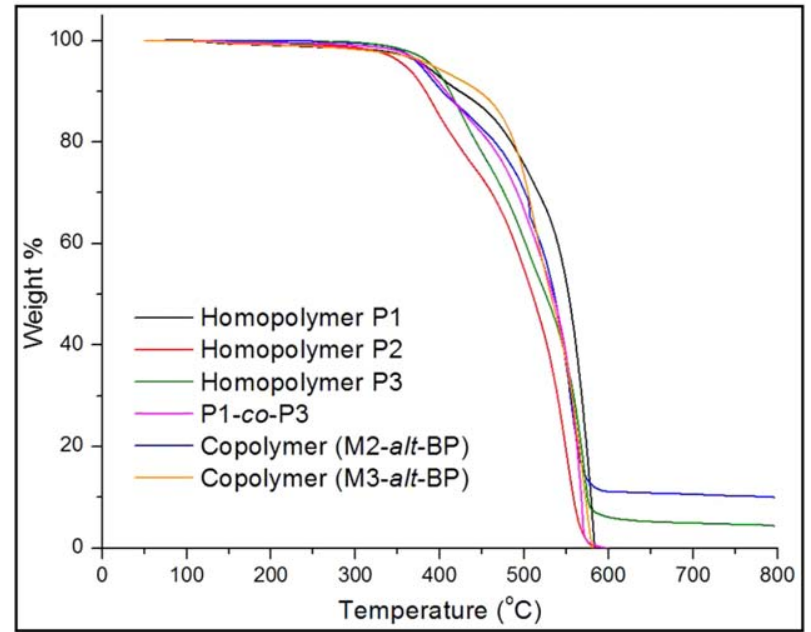

FIGURE 3 TGA thermograms of PFCH aryl ether homo and copolymers (a) in $\mathrm{N}_{2}$ and (b) in air. [Color figure can be viewed in the online issue, which is available at wileyonlinelibrary. com.] 
(a)

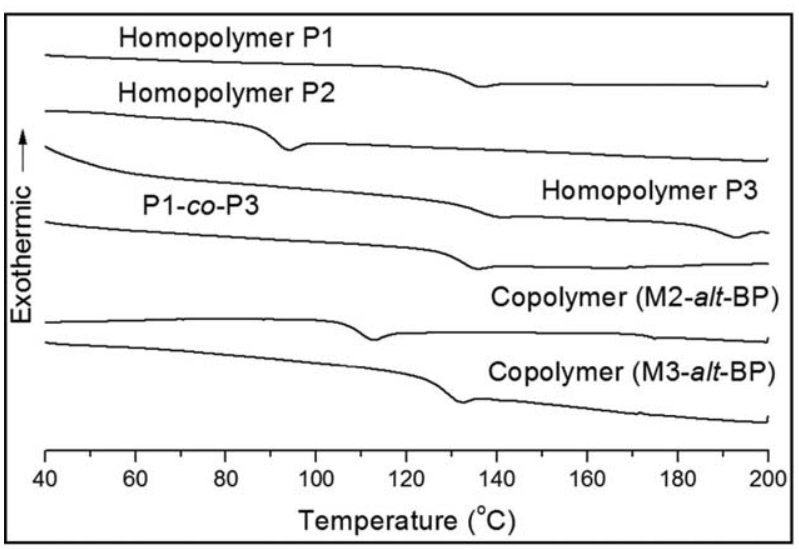

(b)

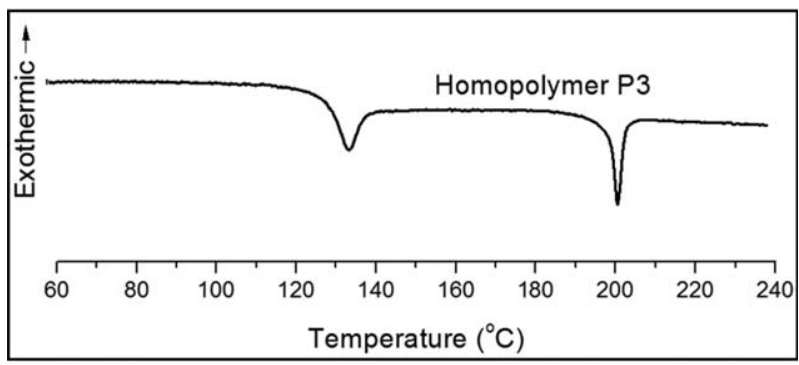

FIGURE 4 (a) DSC thermograms of PFCH aryl ether homo and copolymers; heating and cooling rate: $10{ }^{\circ} \mathrm{C} / \mathrm{min}$. (b) DSC thermogram of homopolymer $\mathrm{P} 3$ with heating rate of $10{ }^{\circ} \mathrm{C} / \mathrm{min}$ and cooling rate of $1{ }^{\circ} \mathrm{C} / \mathrm{min}$.

amorphous hump, whereas homopolymer P2 and P3 yield medium reflections. Homopolymer P2 shows a peak at $19.10^{\circ}$ that has a $\mathrm{d}$ value of 4.643 , with relative crystallinity of $31 \%$. Homopolymer P3 shows a peak at $19.13^{\circ}$ that has a $d$ value of 4.636 , with relative crystallinity of $32 \%$.

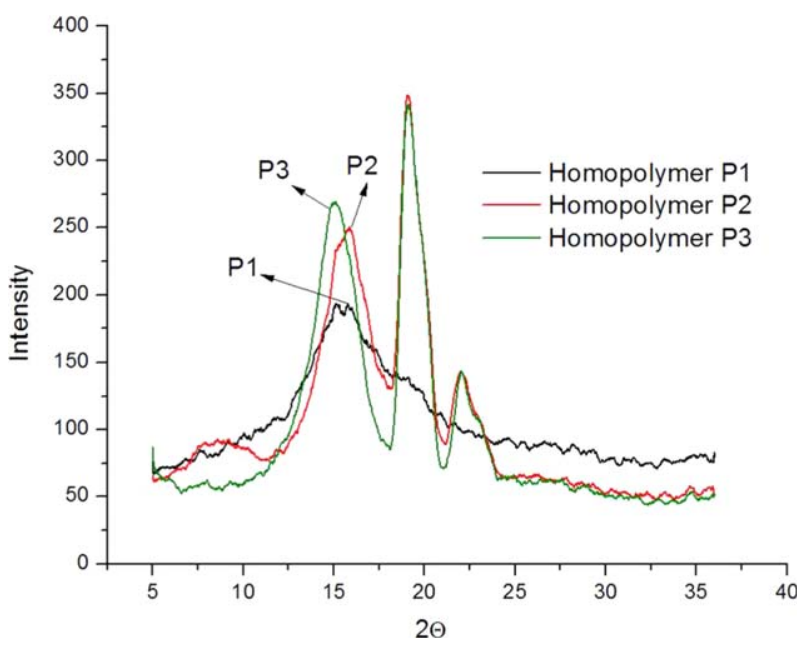

FIGURE 5 WAXRD spectra for homopolymers P1, P2, and P3. [Color figure can be viewed in the online issue, which is available at wileyonlinelibrary.com.]

\section{CONCLUSIONS}

We have successfully synthesized the first step-growth polymerization of commercially available bisphenols and DFCH to yield a new class of fluoropolymers, namely, PFCH aryl ether polymers, in good yield. These polymers display interesting variable thermal properties, depending on the choice of spacer group, $\mathrm{R}$. Also, the synthesized polymers show high thermal stability with $T_{\mathrm{d}}$ at $5 \%$ weight loss ranging from 380 to $440{ }^{\circ} \mathrm{C}$. Furthermore, the intact perfluorocyclohexenyl olefin moiety can be utilized for postpolymerization modifications. The discussed fluoropolymers may find applications in EOs, photonics, or as melt or solution processable resins for thermosetting applications.

\section{ACKNOWLEDGMENTS}

The authors want to express their gratitude toward Intel Corporation (Grant \# 4606175), Welch Foundation (Grant \# AT0041), CEHMS (Grant \# IIP-1035024) and The University of Texas at Dallas for their financial support. The authors also acknowledge NSF-MRI grant (CHE-1126177) used to purchase Bruker Advance III 500 NMR instrument.

\section{REFERENCES AND NOTES}

1 B. Ameduri, B. Boutevin, Well-Architectured Fluoropolymers: Synthesis, Properties and Applications; Elsevier Science: San Diego, 2004.

2 J. Scheirs, Modern Fluoropolymers: High Performance Polymers for Diverse Applications; Wiley: New York, 1997.

3 R. E. Banks, B. E. Smart, J. Tatlow, Organo-fluorine Chemistry: Principles and Commercial Applications; Plenum Press: New York, 1994.

4 L. Wall, Fluoropolymers; Wiley: New York, 1972.

5 S. T. lacono, S. M. Budy, J. Jin, D. W. Smith, Jr., J. Polym. Sci. Part A: Polym. Chem. 2007, 45, 5705-5721.

6 H. Ma, A. K. Y. Jen, L. R. Dalton, Adv. Mater. 2002, 14, 13391365.

7 S. T. lacono, S. M. Budy, J. D. Moody, R. C. Smith, D. W. Smith, Jr., Macromolecules 2008, 41, 7490-7496.

8 L. Eldada, L. W. Shacklette, IEEE J. Sel. Top. Quant. Electron. 2000, 6, 54-68.

9 A. Taguet, B. Ameduri, B. Boutevin, Crosslinking in Materials Science; Springer: Berlin, Heidelberg, 2005, 184, 127-211.

10 G. Tillet, B. Boutevin, B. Ameduri, Prog. Polym. Sci. 2011, $36,191-217$.

11 D. K. Dei, B. R. Lund, J. Wu, D. Simon, T. Ware, W. E. Voit, D. MacFarlane, S. M. Liff, D. W. Smith, Jr., ACS Macro Lett. 2012, 2, 35-39.

12 C. K. Sharon, B. R. Lund, D. W. Smith, Jr., S. T. lacono, Advances in Fluorine-Containing Polymers; American Chemical Society: Washington, DC, 2012; Vol. 1106, p 9-28.

13 T. L. Andrew, T. M. Swager, Macromolecules 2011, 44, 2276-2281.

14 D. A. Babb, B. R. Ezzell, K. S. Clement, W. F. Richey, A. P. Kennedy, J. Polym. Sci. Part A: Polym. Chem. 1993, 31, 34653477.

15 C. M. Timperley, J. Fluorine Chem. 2004, 125, 685-693.

16 J. H. Beale, N. N. Schwartz, G. J. Mantell, J. Polym. Sci. Polym. Lett. Ed. 1978, 16, 67-74. 
17 R. D. Chambers, J. R. Kirk, R. L. Powell, J. Chem. Soc. Perkin Trans. 1 1983, 1239-1242.

18 S. Garg, B. Twamley, Z. Zeng, J. M. Shreeve, Chem.-Eur. J. 2009, 15, 10554-10562.

19 B. Sharma, D. G. VanDerveer, S. M. Liff, D. W. Smith, Jr., Tetrahedron Lett. 2013, 54, 3609-3612.

20 R. G. Plevey, D. J. Sparrow, J. Chem. Soc. Perkin Trans. 1 1976, 573-577.

21 G. A. Powers, R. Stephens, J. C. Tatlow, J. Fluorine Chem. 1982, 20, 555-558.

22 M. Matsui, M. Tsuge, K. Funabiki, K. Shibata, H. Muramatsu, K. Hirota, M. Hosoda, K. Tai, H. Shiozaki, M. Kim, K. Nakatsu, J. Fluorine Chem. 1999, 97, 207-212.

23 R. M. K. Minday, M. Jason, M. J. Bulinski, WIPO WO 2012/ 118602 A1, 3M Innovative Properties Company, 2012.

24 E. Uenveren, WIPO WO 2009/019219 A2, Solvay, 2009.

25 J. A. Creazzo, M. J. Nappa, A. C. Sievert, E. N. Swearingen, U.S. Patent US 2007/0100010 A1, E I Du Pont De Nemours And Company, 2007.
26 M. J. Nappa, U.S. Patent US 2007/0096051 A1, E I Du Pont De Nemours And Company, 2007.

27 J. Thomas, WIPO WO 2007/08204 A1, E I Du Pont De Nemours And Company, 2007.

28 M. Hashimito, T. Takiguchi, S. Okada, U.S. Patent US 2007/ 0259207 A1, 2007.

29 J.-M. Cracowski, B. Sharma, D. K. Brown, K. Christensen, B. R. Lund, D. W. Smith, Jr., Macromolecules 2012, 45, 766-771.

30 H. F. Koch, A. J. Kielbania, J. Am. Chem. Soc. 1970, 92, 729730.

31 J. D. Moody, D. G. VanDerveer, D. W. Smith, Jr., S. T. lacono, Org. Biomol. Chem. 2011, 9, 4842-4849.

32 S. T. lacono, S. M. Budy, D. Ewald, D. W. Smith, Jr., Chem. Commun. 2006, 0, 4844-4846.

33 D. W. Smith, Jr., J. Jin, H. V. Shah, Y. Xie, D. D. DesMarteau, Polymer 2004, 45, 5755-5760. 